\section{Thorax 2010: celebrating the success of an international respiratory journal}

\author{
$\checkmark$ Jadwiga A Wedzicha, ${ }^{1}$ Sebastian L Johnston ${ }^{2}$ \\ EDITOR'S \\ CHOICE
}

This is our last issue as Thorax Editors, and to celebrate our editorship we are delighted to present a special issue of the journal. We are publishing editorials from our Associate Editors on some of the highlights published in Thorax since the first issue of our editorship in January 2003. We hope that these provide some insight into how the journal has influenced clinical practice during this time.

One of our main objectives at the start of the editorship was to increase the global perspective of the journal. We appointed a number of experienced international Associate Editors and this increased our pool of peer reviewers and stimulated an increasing number of submissions from all over the world. The result is that submissions have doubled over our terms as editors. Our aim for the educational content was to make it relevant to every respiratory specialist both in the UK and abroad, and we have published important clinical reviews and many British Thoracic Society (BTS) clinical guidelines on common conditions that have been popular and highly cited. We continued to publish one case report per issue and thus the acceptance rate for these was low, but we decided to convert some of our case reports to 'Images in Thorax' where we published a short report of 200 words accompanied by radiological or pathological images, and also 'Pulmonary Puzzles' in a question and answer format. We are indebted to Mark Fitzgerald from Vancouver, Canada who handled the case reports so enthusiastically for the whole editorship period and also conceived the idea of Images and Puzzles that have been very popular and educational to the readership.

We were also keen to encourage an active journal, and have emphasised the importance of letters that contribute to both the vitality and interest of a journal.

${ }^{1}$ Academic Unit of Respiratory Medicine, UCL Medical School, Royal Free Campus, London UK; ${ }^{2}$ Imperial College of Science, Technology and Medicine, Department of Respiratory Medicine, National Heart and Lung Institute, London, UK
We have had many more submissions of letters than we could publish, and these have been as correspondence with feedback on published papers, together with research letters containing often important original pilot data. There have been many changes in medical publishing since we took over as Editors, and we have tried to implement these for the benefit of Thorax. We instituted a web repository for additional data and information in papers; we had the opportunity of including an On Line First facility to enable rapid publication of papers after acceptance and recently we started producing the first Thorax podcasts. We have been keen to involve younger members of the respiratory community and we started our Lung Alert feature where we published short summaries of papers with a respiratory interest published in other journals. Please read the editorial from Angshu Bhowmik and Jenni Quint who summarise the Lung Alerts feature in this issue.

We were also fortunate to be able to celebrate the 60th anniversary of Thorax in December 2006 with a special edition containing editorials from our past Thorax Editors. This enabled us to compile the history of the journal and how it evolved from a journal publishing articles from UK authors on thoracic surgery, pathology and tuberculosis to its current position as a truly successful international respiratory journal. In November 2006, the current Editorial Board also had the privilege to have a very memorable meeting with past Editors who gave us insights into the work of an Editor in the past, while at the same time providing us with wise advice for the future of the journal. We also published a special edition for the 25th anniversary of the BTS in December 2007. At the start of the editorship we redesigned the front cover to a blue format but then later we decided to have a coloured image on the front, different in each issue to give the journal a more contemporary and interesting outlook.

We are of course aware that we have disappointed a number of authors in decisions on their papers. The number of original papers submitted to Thorax has doubled over the last 7 years and we have kept the number of papers published constant, thus the rejection rate has also increased. One of the greatest concerns from upset authors has been that the peer reviewers have provided favourable reviews, but the Editors subsequently rejected the papers. However, the role of a peer reviewer is to advise on the originality and science in the manuscript, while the role of the Editor is to make sure that the paper is of sufficient priority and interest and that the balance of the journal is right. All our potentially acceptable papers were discussed at an editorial meeting held on Thursdays, when we carefully read all the peer review comments, together with the suggestions of the Associate Editor and Statistical Editor, before making the final decision on each manuscript.

We are delighted that the impact factor for Thorax for 2009 published recently is at 7.041 and this means that the Thorax impact factor has now stayed above 7 for the past 2 years. This increase in the impact factor is due to the high quality papers and reviews that you have all submitted to the journal for publication. We have thus maintained our position as the second highest ranked respiratory journal in terms of impact factor, behind the American Journal of Respiratory and Critical Care Medicine.

We would like to thank the BTS and BMJ Journals (co-owners of the journal) for appointing us as Thorax Editors, trusting us with the work of the journal and for all their support over the years. We would like especially to thank all our Associate Editors who have put so much of their time and expertise into reviewing and editing papers for the journal with such skill. We have been particularly fortunate that most of the Associate Editors have been with us since we formed our editorial team in October 2002 and this continuity has no doubt contributed to the success of the journal. We also had our annual Editors meetings in London during November and these were always well attended and memorable occasions that enabled us to review the progress of the journal and its developments. The Thorax International Advisory Board has been a very important part of the journal and we would like to thank the Board for giving their time to review papers for the journal, attending so loyally our annual breakfast meetings at the American Thoracic Society, contributing to the lively debates and providing us with many suggestions on the direction that we should pursue with Thorax. 
At first the Thorax editorial office was based at the BTS, before moving to BMA House, and we are grateful to our first Editorial Assistant Ed Howard who guided us so well in changing to a new on line submission system for Thorax and who managed the journal so efficiently for us until 2006. Ed was also very talented in enabling some of the more 'social' aspects of the journal, and we recall some very pleasant dinners both at the annual Thorax editors meetings and during the ATS meeting. We would like to thank Julia Dimitriou who took over from Ed and has so very conscientiously managed the journal for us, providing constant support to the whole editorial team, and we are delighted that she has been recently promoted to the post of Thorax Production Editor. In 2008, David Mitchell announced his resignation from the Thorax editorship after 5 years of very dedicated contribution to the journal. We are grateful to all the technical editors who have contributed to making the journal look so professional each month and especially to Liz Stockman who had been the Thorax technical editor for many years, pre-dating our editorship, till 2007. We would like to thank our Thorax managers, initially Andrea Horgan who provided us with many ideas to enhance the journal and also taught us a great deal about publishing, and lately Claire Folkes who has so expertly managed Thorax for us. We would like to thank Alex Williamson Publishing Manager of BMJ Journals who retired at the end of 2007. A number of Thorax editors have had the immense privilege to work with Alex over the years; she was very fond of the journal and gave us all much valued wise counsel. She was instrumental in developing Thorax into the high quality international journal it is today. We are also grateful to Peter Ashman who is the current Publishing Manager.

The peer reviewers are especially important to a journal, and constructive criticism of a paper greatly improves the final published version. Each year we have published the name of the reviewers who helped us over the preceding year and we would like to express our gratitude to all the peer reviewers for helping us to select the very best papers for publication. Unfortunately over the years around one-third of the commissioned peer reviewers have declined to review papers mainly due to increasing professional commitments. We are grateful to the whole international respiratory community for sending us their high quality papers that contributed to the journal's success and please keep sending them! We are leaving a very strong journal in very capable hands with the new Thorax editors Andy Bush and Ian Pavord, to whom we warmly wish every success.

Our objective has been to publish the very best and original respiratory research papers, but we have also strived to provide in Thorax each month something of interest to all those involved with the care of respiratory patients. Back in January 2003, we wrote in our inaugural Thorax Editorial that the success of Thorax will ultimately depend on the influence that the journal has on the readership' and we hope we have achieved the goals and had a positive influence on our readership. We are also privileged that, through the editorship, we have been able to serve our respiratory community both in the UK and abroad. We hope that you agree with us that in September 2010 Thorax can celebrate its position as an important international respiratory journal and that our mission as Thorax Editors has been accomplished.

\section{Competing interests None.}

Provenance and peer review Commissioned; not externally peer reviewed.

Thorax 2010;65:755-756

doi:10.1136/thx.2010.146662

\section{Diagnosing lung cancer earlier in the UK}

\section{Richard B Hubbard, David R Baldwin}

The 30326 deaths from lung cancer in England and Wales in 2008 represent 22\% of the total mortality burden from cancer in that year. ${ }^{1}$ The next two most common causes of cancer death were colorectal cancer $(10 \%)$ and breast cancer (8\%). These familiar statistics outline the enormous impact that lung cancer continues to have on public health in the UK.

The dramatic fall in the prevalence of smoking in the UK over the last 60 years means that the lung cancer epidemic in the

Division of Respiratory Medicine, University of Nottingham, Nottingham, UK

Correspondence to Dr Richard Hubbard, Division of Respiratory Medicine, Clinical Sciences Building, City Hospital, Hucknall Road, Nottingham NG5 1PB, UK; richard.hubbard@nottingham.ac.uk
UK has peaked, particularly in men, and this is good news. ${ }^{2}$ In order to protect future generations of people in the UK from developing lung cancer, however, steps to drive down the prevalence of smoking as much as possible, and across all sectors of society, remains a pressing public health priority. ${ }^{34}$ This will inevitably need a broad spectrum of approaches. ${ }^{5} 6$

People who are currently at high risk of developing lung cancer, but do not yet have the disease, may benefit in the future if an effective screening programme can be developed to detect early subclinical disease. At the moment the use of CT imaging seems the approach most likely to succeed, but no trial yet has been able to demonstrate a reduction in mortality. A number of trials are currently ongoing, however, and more definitive evidence is expected between 2012 and 2016. ${ }^{7-13}$ Recently, a feasibility study for a randomised trial of CT screening in the UK has been completed and currently the arrangements are being finalised to undertake a pilot randomised trial. We hope that this project will stimulate more research in this area in the UK, including a trial powered to detect a mortality benefit of screening as well as research into the natural history of early lung cancer detected by CT screening. ${ }^{14} 15$ Research into other screening approaches using more innovative methods is also ongoing but at an early stage. ${ }^{16} 17$

Unfortunately, screening will not help people who are being diagnosed with lung cancer now in the UK. Consequently, those of us who work in healthcare have an important duty of care to these people to ensure that the cancer diagnosis is made at the earliest possible moment and that the most effective currently available treatments are given in a timely fashion in order to improve survival and/or palliate disease. With this in mind, a number of papers published in Thorax have recently 